\title{
Prevalence and Identification of Ixodide Ticks in Cattle in Lalo Assabi District, West Wollega Zone, West Oromia, Ethiopia
}

\author{
Kebede A*, Lemmi E and Dugassa J \\ School of Veterinary Medicine, College of Medical and Health Science, Wollega \\ University, Ethiopia
}

*Corresponding author: Abriham Kebede, School of Veterinary Medicine, College of

\section{Research Article \\ Volume 3 Issue 3}

Received Date: August 07, 2018

Published Date: September 07, 2018 Medical and Health Science, Wollega University, P.O. Box, 395, Nekemte, Ethiopia, Tel: 251-917-095-077; Email: abrahamkebede2016@gmail.com

\section{Abstract}

Ticks are important parasite of cattle that cause huge economic loss at private and national level. Therefore, the cross sectional study was conducted from October 2016 to June 2017 in Lalo Assabi district of West Wollega Zone. The aims of the study were to determine the prevalence of tick infestation and to identify their predilection site, possible risk factors and distribution in the rural and urban area of Lalo Assabi districts. Peasant Associations (PAs), sex, age, body conditions of animals and ticks genera were major factors involved in the study. A systematic random sampling study design was followed to collect samples. From the total of 384 cattle, 265 (69\%) cattle were found to be infested with tick. Out of five peasant associations examined, highest prevalence (80.4\%) was recorded at Barko Daleti Peasant Associations. Highest prevalence (82\%) was observed in male than in female animals (59\%). Relatively highest prevalence was recorded in adult animals (70.7\%) as compared with young and old age animals. Amblyomma, Boophilus and Rhipicephalus were tick genera with infestation rate of $30.7 \%, 23.2 \%$ and $15.1 \%$, respectively. Animals with good body condition were relatively affected (74.1\%). Different tick genera have different predilection sites. Amblyomma had strong preference for udder or scrotum (19.3\%), Boophilus was highly prevalent on Udder or Scrotum and Genus Rhipicephalus was highly found attached to Dewlap (21.1\%). However, there was no significant variation on the prevalence of tick infestations $(\mathrm{P}>0.05)$. The study revealed that ticks are the most important ectoparasites and cause economic losses in the area. Animal's husbandry and management improvement is warranted to reduce the rate of tick's infestation.

Keywords: Bovine; Lalo Assabi; Prevalence; Ticks 
Abbreviations: CSA: Central Statistical Agency of Ethiopia; DVM: Doctor of Veterinary Medicine; EVA: Ethiopia Veterinary Association; FAO: Food and Agricultural Organization; GDP: Gross Domestic Product; ILRI: International Livestock Research Institute; PAs: Peasant Associations; TBD: Tick Born Diseases; US: United State; VBD: Vector and Vector Born Disease.

\section{Introduction}

Ethiopia, located in the horn of Africa between latitude $30^{\circ}$ North to $15^{0}$ North of the equator and the longitude from $33^{\circ}$ East to $48^{\circ}$ East is agrarian country with an estimated a total land area of $1,101,000 \mathrm{~km}^{2}$. The proportion of a total population agriculture sector is 82.4\% [1]. According to CSA estimate, the livestock population is about 30 million heads of cattle, 24 million sheep, 18 million goats, 72 million equines, 1.25 million pigs, and 55.6 million poultry [2]. The Ethiopian contributes only $15 \%$ of the GDP. Total heard meat offtake is estimated at around $7 \%$ annually which is perhaps one third lower than the average for tropical Africa. Cattle are the prime resource for the people and government of Ethiopia [1]. However, the occurrence of the disease and parasite are the major contributing factors that have impeded the full exploitation of the cattle potential [3].

Vector and vector born disease (VBD) are the major constraints to the developments to the of viable livestock industries where they occur [4]. The tick and tick born diseases (TBD) are widely distributed throughout the world particularly in tropical and subtropical countries, which cause a tremendous loss in livestock production [5]. In most parts of Africa, including Ethiopia tick and TBD, together with tsetse and trypanosomosis are economically very important disease [6]. The economic losses caused by tick and TBDs in cattle alone are estimated at US \$13.9- 18.7 billion annually worldwide [7]. The problem is severing in developing countries where the resource for control and eradication is very limited [8]. Among developing countries in Ethiopia, the ticks occupy the first place among the external parasite, and the economic loss incurred when they infest livestock, particularly is enormous [9].

According to Walker, et al. [10] ticks are considered to be the most important to the health of domestic animals in Africa comprise about seven genera. Among these tick genera, the main ticks found in Ethiopia are Amblyomma, Boophilus, Haemaphysalis, Hyalomma, Rhipicephalus. The most important and wide spread tick species are Amlyomma varigatum (vector of cowdria rumminantum and Theileria mutans) and Boophilus decoloratus (vector of Anaplasma marginale and Babesia bigemina) [11]. These ticks are important transmitters of disease and can damage the hides and skins, and interfere with meat production. Extensive survey have been also carried out on the distribution of tick species on livestock in different regions of the country in which different tick species such as Boophilus decoloratus, Amlyomma varigatum, R. eversi eversi, Haylomma marginatum rufipes, Hyalomma truncatumi , Ambyomma cohaerance, Amlyomma gemma, Alyomma elide, Rhipicephalus pulchellus are also frequently reported in many tick survey carried out in the country $[12,13]$.

Even though there is high risk of tick infestation in the study area, there is no detail current study on tick population, species of tick and the most predominant tick species causing nausis to animal population and high economic losses is not identified.

Hence the objective of the study is:-

$>$ To identify the main tick genere infesting the cattle and their distribution in the rural and urban area of Lalo Assabi districts.

$>$ To identity predilection site of important tick genus infesting cattle

$>$ To asses possible risk factors for tick parasite in cattle

\section{Materials and Methodology}

\section{Study Area}

The study was conducted in Lalo Assabi district in west wollega zone of Oromia Regional State from October 2016 to June 2017. The district capital town, Enango, is located at $461 \mathrm{~km}$ to the East of Addis Ababa, the capital city of Ethiopia. Geographically, the district lies between $9^{\circ}-20^{\circ} \mathrm{N}$ latitudes and $35^{\circ}-45^{\circ} \mathrm{E}$ longitudes. The total area coverage of the district is estimated at 76 to 261 hectares of land. The altitude of the district ranges from $1500 \mathrm{~m}$ to $1900 \mathrm{~m}$ above sea level with the annual rain fall of $1750 \mathrm{~mm}$ and the mean annual minimum and maximum temperature of 20 and $30^{\circ} \mathrm{C}$, respectively. Lalo Assabi is bordered in the east by Ghimbi district, in the west by Guliso district, in the north by Boji dirmaji district and in the south west by Ganji district and south east by Homa district.

According to the district livestock and fishery office recorded data of the total population sizes of the district would 119460 in 2016, out of the total population the registered cattle population is 25411 , sheep 16806 , goats 1202 , horse 5 mule 114 , donkey 4115 , poultry 71807 and 
53520 honey bees. This includes both exotic and local breeds of animals.

\section{Study Population}

Among population of animals the study was conducted on cattle populations that are present in rural and urban area of Lalo Assabi district. All the cattle sampled were local breeds kept under extensive production system.

\section{Study Design}

A cross sectional study design was conducted to identify important tick species infesting cattle in from five purposively selected peasant associations (i.e. Tosio mole, Warago arsama, Batro chokorsa, Barko dalati and Enango town) of Lalo assabi district during October, 2016 to June, 2017. PAS, Age, sex and body condition of the animal was considered as variables on the prevalence of ticks.

\section{Sample size determination}

Since there was no previous study conducted on ticks in cattle in the area, sample size was determined by assuming $50 \%$ prevalence of tick infestation in the area. The desired sample size for the study was calculated by the formula given by Thrusfield [14]. Therefore, if 95\% confidence interval is required with $5 \%$ margin of error, the sample size (n) is determined by the formula:-

$$
n=z^{2} p(1-p) / w^{2}
$$

Where $\mathrm{n}=$ sample size, $\mathrm{p}=$ prevalence, $\mathrm{W}=$ margin of error and $\mathrm{z}$ is a constant from normal distribution table. Accordingly, the sample size (n) in this case was determined as follows:

$\mathrm{n}=(1.96) 2 \times 0.5(1-0.5) /(0.05) 2=384$.

Therefore, sample size of 384 cattle was examined in the study.

\section{Collection of Ticks}

The whole body surface of the animals were examined for the presence or absence of ticks and half body tick collection methods on the alternate sides were used to collect ticks from the animals and the result doubled to assess the overall burden of ticks $[10,15]$. Ticks were collected from the nine (9) different body sites such as ear, neck, dewlap, brisket, abdomen, udder/scrotum, perineum, ano-vulva and under the tail after proper physical restraining of the animals. During collection, ticks were removed manually from different attachment sites of the animal body by a rotating manner to retain their body parts for identification [16]. Data collection format was used to register the data during tick collection and proper labeling was made on universal bottles with permanent marker. Date of collection, address, species, sex, age, code of animal and sites of attachment were included in the labeling. Ticks collected from different body sites were preserved in different universal bottles, prefilled with $70 \%$ ethanol, for each animal. Then, the sample transported to Bedelle Veterinary Regional Laboratory for further identification of the ticks at genera level. Finally, ticks were identified, counted and recorded up to species within 5 days of collection using stereomicroscope [17].

\section{Identification of Ticks}

Stereomicroscope was used to identify the ticks based on their morphological features such as mouth parts, scutum, and color of legs, festoons, interstitial punctations, presence or absence of adanal shields, posterior groove and marginal spots. The taxonomic keys of Kaiser and Walker, et al. $[10,15]$ were used to identify the ticks under stereomicroscope by manipulating each tick with wire loop.

\section{Data analysis}

Analysis of obtained data was done by Chi square $\left(\mathrm{x}^{2}\right)$ and independent samples test were used to test the association between ticks infestation with different factors (age, sex and body condition score). For this analysis, SPSS, version 20 was used.

\section{Results}

\section{Prevalence Based on PAS, Sex, Age and Body Conditions of Animals}

A total of 384 cattle from five Peasant Associations (PAs) were examined and overall of 265 (69\%) cattle were found to be infested by different genera of ticks. Highest prevalence (80.4) was recorded at Barko Daleti Peasant Associations (Table 1).

Out of 384 cattle examined, 217 of them were females and 167 were males in which 128 (59\%) and 137 (82\%) of them were infested by ticks, respectively. Different age groups of animals were observed for tick's infestation. Highest numbers of adult animals (229) were examined as compared with young (109) and old (46) age animals. Relatively highest prevalence was recorded in adult animals $(70.7 \%)$. The genera of ticks encountered Amblyomma, Boophilus and Rhipicephalus with relative infestation rate of $30.7 \%, 23.2 \%$ and $15.1 \%$, respectively. Also tick infestation was observed in relation to body 
condition and animals with good body condition were relatively affected (72.3\%) (Table 1).

\begin{tabular}{|c|c|c|c|c|c|c|c|}
\hline \multirow{2}{*}{ Factors } & \multirow{2}{*}{ No. of examined } & \multirow{2}{*}{ No. of infested } & \multirow{2}{*}{$\begin{array}{c}\text { Prevalence } \\
(\%)\end{array}$} & \multirow{2}{*}{ P-value } & \multirow{2}{*}{ OR } & \multicolumn{2}{|c|}{ 95\%CI } \\
\hline & & & & & & Lower & Upper \\
\hline \multicolumn{8}{|c|}{ PAS } \\
\hline Tosio Mole & 84 & 55 & 65.5 & 0.388 & 1.342 & 689 & 2.616 \\
\hline Werego Arsema & 96 & 62 & 64.6 & 0.312 & 1.396 & 0.731 & 2.665 \\
\hline Batro Chokorsa & 70 & 46 & 65.7 & 0.328 & 1.414 & 0.706 & 2.832 \\
\hline Barko Daleti & 56 & 45 & 80.4 & 0.375 & 0.694 & 0.31 & 1.555 \\
\hline Enango Twon & 78 & 57 & 73.1 & - & - & - & - \\
\hline \multicolumn{8}{|c|}{ Age } \\
\hline Young & 109 & 72 & 66.1 & 0.08 & 0.91 & 0.45 & 1.87 \\
\hline Adult & 229 & 162 & 70.7 & 0.8 & 0.71 & 0.364 & 1.37 \\
\hline Old & 46 & 31 & 67.4 & 0.3 & - & - & - \\
\hline \multicolumn{8}{|c|}{ Sex } \\
\hline Male & 167 & 137 & 82 & 0.13 & 1.4 & 0.91 & 2.159 \\
\hline Female & 217 & 128 & 59 & - & & & \\
\hline \multicolumn{8}{|c|}{ Body condition } \\
\hline Good & 112 & 83 & 74.1 & - & - & - & - \\
\hline Medium & 132 & 94 & 71.2 & 0.85 & 1.06 & 0.6 & 1.85 \\
\hline Poor & 140 & 88 & 62.9 & 0.09 & 1.59 & 0.93 & 2.72 \\
\hline Total & 384 & 265 & & & & & \\
\hline
\end{tabular}

Table 1: Tick Prevalence based on PAS, sex, age and body conditions of animals.

\section{Prevalence Based on Predilection Sites}

It was revealed in this study that different tick genera have different predilection sites. According to this result, Amblyomma had strong preference for udder or scrotum (19.3\%), perineum (13.4\%), Neck (11.8\%) and (10.9\%).
Boophilus was highly prevalent on Udder or Scrotum followed by (16.9\%) ear and Dewlap (15.3\%). Genus Rhipicephalus was highly found attached to Dewlap $(21.1 \%)$ and followed by ear $(15.8 \%)$ and ano-vulva (14\%). Generally, different genera of ticks were attached to Udder or Scrotum (12.5\%) which followed by Dewlap (10.2\%) (Table 2).

\begin{tabular}{|c|c|c|c|c|c|}
\hline \multirow{2}{*}{ Predilection site of Ticks } & \multicolumn{4}{|c|}{ Tick Genera } & \multirow{2}{*}{ Total (\%) } \\
\cline { 2 - 5 } & None & Amblyomma (\%) & $\begin{array}{c}\text { Boophilus } \\
\text { (\%) }\end{array}$ & $\begin{array}{c}\text { Rhipicephalus } \\
\text { (\%) }\end{array}$ & \\
\hline None & 119 & - & - & - & $119(31.8)$ \\
\hline Ear & - & $14(11.8)$ & $15(16.9)$ & $9(15.8)$ & $38(9.9)$ \\
\hline Neck & - & $13(10.9)$ & $10(11.2)$ & $3(5.3)$ & $26(6.8)$ \\
\hline Dewlap & - & $13(10.9)$ & $14(15.3)$ & $12(21.1)$ & $39(10.2)$ \\
\hline Brisket & - & $10(8.4)$ & $8(9)$ & $7(12.3)$ & $25(6.5)$ \\
\hline Abdomen & - & $10(8.4)$ & $3(3.4)$ & $5(8.8)$ & $18(4.7)$ \\
\hline Udder/Scrotum & - & $23(19.3)$ & $18(20.2)$ & $7(12.3)$ & $48(12.5)$ \\
\hline Perinium & - & $16(13.4)$ & $5(5.6)$ & $1(1.8)$ & $22(5.7)$ \\
\hline Ano-vulva & - & $9(7.6)$ & $8(9)$ & $8(14.0)$ & $25(6.5)$ \\
\hline Under tail & - & $9(7.6)$ & $7(7.9)$ & $5(8.8)$ & $21(5.5)$ \\
\hline Total & $\mathbf{1 1 9 ( 3 1 )}$ & $\mathbf{1 1 9 ( 3 1 )}$ & $\mathbf{8 9 ( 2 3 . 2 )}$ & $\mathbf{5 7 ( 1 4 . 8 )}$ & $\mathbf{3 8 4}(\mathbf{1 0 0})$ \\
\hline
\end{tabular}

Table 2: Tick genera and their attachment sites. 


\section{Open Access Journal of Veterinary Science \& Research}

\section{Discussion}

Different tick species are widely distributed in Ethiopia and a number of researchers reported the distribution and abundance of tick species in different parts of the country $[6,18]$. The current study reveals that, total of 384 cattle from five Peasant Associations (PAs) were examined and overall of 265 (69\%) cattle were found to be infested by different genera of ticks.

This is relatively high when we compare with the reports of Tadesse and Sultan [19] with overall prevalence of $59.5 \%$. However, the results of this study is lower than the reports of Alemu, et al. [20] and Gedlu, et al. [21] who reported the overall prevalence of 81.5 and $74 \%$, respectively. On the other hand, various research works have found less prevalence of tick infestation than the current study including the reports of Addis and Onu and Shiferaw [22] who indicated tick prevalence of 25.64 and $14.5 \%$, respectively.

It also greater than the previous works of different researchers including Onu and Shiferaw [22], Abebe, et al. [23], Tadesse and Sultan [19], and Bedaso, et al. [24] with prevalence of $4.75,4.2,32.2$, and $41 \%$, respectively. It is also less than the result of Messele in Bahir Dar with prevalence of $75.91 \%$ and in Assosa with prevalence $75.91 \%[3,25]$. The difference could be due to the difference in the agro climatic condition of the study areas, because tick activity is influenced by rainfall, altitude and atmospheric relative humidity according to Pegram, et al. [26].

A relatively high tick infestation (80.4\%) was recorded at Barko Daleti Peasant Associations. The high prevalence at Barko Daleti might be due to having large common grazing area where they stay the whole day time. It was high prevalence when compared with the report from West Haraghe Zone by Zelalem, et al. [27]. However, prevalence of tick infestation was statistically not significant $(\mathrm{P}>0.05)$ in all peasant associations (Table 1$)$.

Amblyomma is the first prevalent tick genera in the area (30.7\%) while Boophilus (23.2\%) and Rhipicephulus $(15.1 \%)$. This result agree with previous studies on survey of the tick species in Jimma zone, western Ethiopia conducted by Pegram, et al. [26], Abebaw [28] and De Castro [7]. They found high prevalence of Amblyomma in their study area.

Boophilus was the second abundant tick genera in the area with prevalence of $23.2 \%$. This result is slightly greater the survey done in Jimma province with the prevalence of $19.98 \%$, but it was slightly higher than the survey done in East Haraghe zone, Gursum district with the prevalence of $10.37 \%[29,30]$. This result is slightly in agreement with the report of Tamiru, et al. [31] who indicated $15.4 \%$ prevalence.

Rhipicephulus was the third tick genera found to be occurred in study area with prevalence of $15.1 \%$. The result is greater than the finding done in and around Jimma with the prevalency of 3.32\% [29]. However this result is slightly disagree with the previous work reported with prevalence of $13.5 \%$ by Tamerat, et al. (2015) and Alemu, et al. [20] with prevalence of $11.5 \%$, and less than the results of Abdisa [32] and Huruma, et al. [33] who reported 50.9 and $53.4 \%$, respectively. This may be due to environmental condition which is not favorable to their survival, humid and highland nature of the area [26].

The number of male ticks was higher than the number of females in all tick genera identified. This finding agrees with the reports of Abdisa [32] and Badaso, et al. [24] who reported similar results. This high number of male ticks may be attributed to the fact that fully engorged female tick drops off the host to lay eggs while males tend to remain on the host up to several months to continue feeding and mating with other females on the host before dropping [6]. The reason that female $B$. decoloratus outnumber the males could be due to the small size of males which may not be seen during collection [34].

In relation to the attachment sites of ticks on the host body, different tick species were found to be having different predilection sites in this study. Accordingly, Amblyomma had strong preference for scrotum/udder, perineum and dewlap where as Rhipicephalus highly prefer under the tail and ano-vulva. However, more or less Boophilus found located throughout the body with a few difference on different body parts. The result of this study is in line with the results of Stachurski [35] who stated that short hypostome ticks like Rhipicephalus usually prefer upper body parts including nape of neck and margin of anus and under tail, while long hypostome ticks like Amblyomma attaches to lower parts of the animal body which is also the case in the current study $[36,37]$.

\section{Conclusion and Recommendations}

The current study identified three genera of ticks in the study area. Amblyomma was highly prevalent which is followed by Boophilus genus. The result of the study 
indicated that ticks were the most wide spreaded and prevalent parasite affecting the cattle with an overall prevalence of $69 \%$. This indicates that the prevalence of the tick is high in the study area. However the prevalence of ticks is high in the area, there was not yet strategic control of external parasites including ticks. Therefore, sustainable tick control program should be put in place in order to reduce the current trend of prevalence to lower level. Based on the above research result and conclusion, the following recommendations are forwarded:-

$>$ Awareness on tick control should be promoted among livestock owners

> All stakeholders concerned with livestock production and healthcare programs should make concerted effort to plan and implement effective control programs on ticks and other external parasites.

> Sufficient budget should be allocated the government and the woreda administrative for the purchase of chemical sprays and spraying equipment on yearly basis.

$>$ Further research should be conducted to identify tick up to its species for combating species related problems.

\section{Conflict of Interests}

The authors have declared that there is no any conflict of interests.

\section{Acknowledgement}

We were like to express our gratitude to Wollega University, College of Medical and health science, School of Veterinary Medicine and the Staff of School of Veterinary Medicine for inspiration and comprehensive moral support. Also we were like thanks people of Lalo Assabi district of West Wollega Zone for supporting us through allowing of their animals to take sample from them and other related.

\section{References}

1. CSA (2002) Ethiopian Statistical abstract Addis Ababa Ethiopia. Central statistics Authority.

2. CSA (2003) Number of livestock and poultry in different regions of Ethiopia, Addis Ababa, Ethiopia. Central statistics Authority.

3. Mesele A (1989) Bovine tick survey in Bahir Dar awarja. Faculty of Veterinary Medicine, Addis Ababa University, Ethiopia.
4. Mekuria B (1987) A preliminary survey of ticks on four species of domestic animals in Nekemte awraja. DVM Thesis, Faculty of Veterinary Medicine, Addis Ababa University, Ethiopia, pp: 1-35.

5. Kettle DS (1995) Medical and veterinary Entomology. $2^{\text {nd }}(E d n),. C A B$ international, Wallingford, Oxon, UK.

6. Solomon G, Nigist M, Kassa B (2001) Seasonal variation of ticks on calves at sebeta in western Shoa zone. Ethiop Vet J 7: 17-30.

7. De castro JJ (1997) Sustainable tick and tick born disease control in Livestock control improvement in developing countries. Veterinary parasitology 71(23): 77-79.

8. FAO (1984) Ticks and Ticks born disease control. A practical field manual, FAO, Rome, pp: 1-299.

9. Feseha G (1983) Notes on tick species and tick born disease domestic anima in Ethiopia. DVM Thesis, Faculty of Veterinary Medicine Debrezeit, Ethiopia.

10. Walker AR, Boutter A, Estrada-pena A, Horak IG, Latif AA, et al. (2003) Ticks of Domestic Animals in Africa. A Guide to Identification of Tick Species. Bioscience Reports-42 Comiston Drive, Edinburgh EH10 5QR, Scotland, UK, pp: 183-210.

11. Abebaw G (2004) Seasonal dynamics and host preference of Boophilus decoloratus on naturally infested cattle in Jimma zone, south western Ethiopia. Ethiop Vet J 18: 19-28.

12. Seyoum Z (2001) Study of ticks and tick born diseases on cattle at Girana in North Wallo zone. Ethiopian veterinary association 15 : 234-241.

13. Solomon G (2007) Distribution and seasonal variation of ticks on cattle at Ghibe Tolly in Central Ethiopia. EVT 11: 121-139.

14. Thrusfield M (2007) Veterinary Epidemiology. Government Department of Navy Bureau. $3^{\text {rd }}$ (Edn.), Black Well Science Ltd: 18, UK.

15. Kaiser MN (1987) Ethiopia, Report on tick taxonomy and biology, AG: DP. ETH/83/023 Consultant report. Food and Agricultural Organization of the United Nations. 


\section{Open Access Journal of Veterinary Science \& Research}

16. Wall R, Shearer D (2001) Veterinary Ecto-parasites, Biology, Pathology and Control. 7th (Edn.), Black Well Science, London, England, pp: 221-224.

17. Hendrix CM (1998) Diagnostic Veterinary Parasitology. 2nd (Edn.), Mos by press, USA, pp: 169199.

18. Goshu S, Azhahianambia P, Yadav MP (2007) Upcoming and future strategies of tick control: a review. J Vet Borne Dis 44(2): 79-89.

19. Tadesse B, Sultan A (2014) Prevalence and distribution of tick infestation on cattle at Fiche Selale, North Shoa, Ethiopia. Livest Res Rural Dev 26(8).

20. Alemu G, Chanie M, Mengesha D, Bogale B (2014) Prevalence of Ixodide ticks on cattle in Northwest Ethiopia. Acta Parasitol Glob 5(2): 139-145.

21. Gedlu M, Mohamed A, Kechero Y (2014) Determination of the prevalence of ixodid ticks of cattle breeds, their predilection sites of variation and tick burden between different risk factors in Bahir Dar, Ethiopia. Glob Vet 13(4): 520-529.

22. Onu SH, Shiferaw TZ (2013) Prevalence of ectoparasite infestations of cattle in Bench Maji Zone, Southwest Ethiopia. Vet World 6(6): 291-294.

23. Abebe R, Fantahun T, Abera M, Bekele J (2010) Survey of ticks (Acari: Ixodidae) infesting cattle in two districts of, Somali Regional State. Ethiopia Vet World 3(12): 539-542.

24. Badaso M, Abebe B, Degefu H (2014) Species composition, prevalence and seasonal variation of tick tick in and around Haramaya town, Ethiopia. J Vet Med Anim Health 6(5): 131-137.

25. Bossena F, Abdu M (2012) Servey on distribution of tick species in and around Assosa town, Ethiopia. Res J Vet Sci 5: 32-41.

26. Pegram G, Hoogstraal H, Wassef $H$ (1981) Ticks (Acariixodidea) of Ethiopia Distribution, Ecology and Host Relationships of species infecting livestock. Bull Entomol Res 71(3): 339-359.

27. Zelalem A, Asfaw E, Alemayehu F, Belay D, Ala, D, et al. (2016) Prevalence of Bovine Hard Ticks in Chiro District, West Hararghe Zone, East Oromiya. Acta Parasitol Globalis 7(2): 66-73.
28. Abebaw G (1994) Seasonal dynamics of ticks (Amlyomma cohaerence and boophilus decoloraus) and development of a management plan for tick and born diseases control on cattle in Jimma zone, Southwestern Ethiopia. Institute of Agronomy and Animal production in the Tropics, George- AugustUniversity, Gottingen.

29. Chali E, Melaku M, Negero J (2017) Study on cattle tick species frequency distribution in and around Jimma provence of Ethiopia. Journal of parasitology and Vector biology 9(4): 34-38.

30. Tesgera T, Regasa F, Giro B, Mohammed A (2017) Study on prevalence and Identification of Ixodid ticks in cattle Gursum district, East Hararghe zone of Oromia Regional state of Ethiopia. Journal of parasitology and vector biology 9(4): 27-33.

31. Tamiru T (2008) Survey of Bovine tick species in and around Asela Town. DVM Thesis, School of Veterinary Medicine, Jimma University, Jimma, Ethiopia, pp: 1539.

32. Abdisa R (2012) Prevalence of Ixodid ticks on cattle in Welmera district, West Shoa zone of Ethiopia. DVM Thesis, Haramaya University, College of Veterinary Medicine, Haramaya, Ethiopia.

33. Huruma G, Abdurhaman M, Gebre S, Deresa B (2015) Identification of bovine tick species and their prevalence in and around Sebeta Town, Ethiopia. J parasitol vector boil 7(1): 1-8.

34. Tessema T, Gashaw A (2010) Prevalence of ticks on local and cross breed cattle in and around Asella town, southeast Ethiopia. Ethiop Vet J 14(2): 79-89.

35. Stachurski F (2000) Invasion of West African cattle by the tick Amblyomma variegatum. Med Vet Entomol 14(4): 391-399.

36. Hoogstraal H (1956) African Ixodidae, (I) Rick of Sudan with special to equatorial, province and with preliminary review of the genera Boophilus. Margaropus. Hyalomma). Res Rep N.M.005050.2907.U.S government department of Navy. Bur Med Surg Washington DC, pp: 200-1101.

37. Tiki B, Addis M (2011) Distribution of ixodid ticks on cattle in and around Holeta town, Ethiopia. Glob Vet $7(6):$ 527-531. 